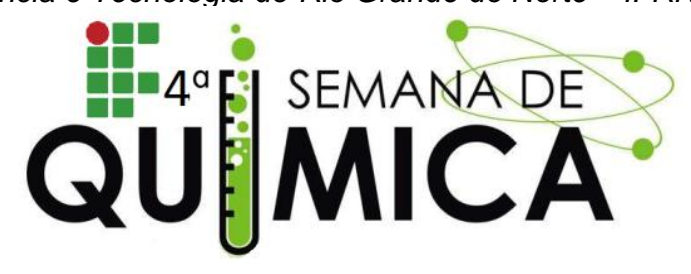

\title{
A POLUIÇÃO CAUSADA PELAS CERÂMICAS NO VALE DO ASSU
}

\author{
SANTOS, W. A. X. (IFRN), VARELA, J.G. (IFRN), BEZERRA, D. P. (IFRN)
}

Palavras Chave: Cerâmica, Poluição, Vale do Assu.

\section{INTRODUÇÃO}

A queima dos fogos cerâmicos causa grande poluição ao meio ambiente. Baseado nessa preocupação, desenvolvemos uma experiência propondo um novo combustível fundamentado na mistura da reutilização do óleo vegetal com a serragem da madeira para a queima dos fornos cerâmicos.

A queima dos fornos cerâmicos causa grande poluição. Baseado nessa preocupação, desenvolvemos uma experiência propondo um novo combustível fundamental na mistura da reutilização do óleo vegetal com a serragem da madeira para a queima dos fornos cerâmicos.

Propor um novo material próprio para a combustão dos fornos cerâmicos, como alternativa para reduzir a gravidade da poluição ao meio ambiente no vale do Açu/RN.

\section{METODOLOGIA}

Para o desenvolvimento deste estudo foi realizado uma pesquisa de trabalhos acadêmicos, visitas em indústria ceramista da região e entrevistas com seus representantes. Com isso, foi possível delimitar quais as possíveis alternativas de substituição da lenha, considerando os diversos materiais disponíveis.

\section{RESULTADOS E DISCUSSÕES}

Dos materiais alternativos para o uso da lenha, o pó de serragem já é utilizados pelas indústrias ceramistas. Os valores do poder calorífico da lenha, do pó de serragem e do óleo (outro possível combustível alternativo para ceramistas) encontram-se na tabela 1 como forma de se ter um comparativo desses combustíveis.
Tabela 1 - Poder calorífico de combustíveis ${ }^{1,2}$.

\begin{tabular}{c|c}
\hline AMOSTRA & $\begin{array}{c}\text { PODER CALORIFICO } \\
\text { (Kcal/Kg) }\end{array}$ \\
\hline Madeira (lenha) & 4.732 \\
\hline Carvão mineral & 2.886 \\
\hline Óleo cru & 2.224 \\
\hline
\end{tabular}

O pó de serragem tem maior área de contato com o oxigênio para a queima o que resulta em uma queima mais completa e reduzindo a produção emissão de CO (monóxido de carbono) e "black carbon" ou carbono elementar (popularmente conhecido como fuligem). Isso resulta em queima com formação de uma fumaça mais branca e com menos material particulado.

\section{CONCLUSÃO}

Após estudos e experimentos, percebemos que a junção da reutilização do óleo vegetal com a serragem da madeira, se transforma num combustível alternativo para a minimização da poluição na queima dos fornos cerâmicos, em comparação com a combustão feita a lenha, que atualmente ainda é predominante no vale do Açu/RN.

\section{REFERÊNCIAS}

1 QUIRINO F. Waldir ${ }^{1}$; VALE T. Ailton ${ }^{2}$. PODER CALORÍFICO DA MADEIRA E DE MATERIAIS LIGNOCELULÓSICOS. Publicado na Revista da Madeira n 89 abril 2005 pag 100-106.

2 ALMEIDA N. Alexandre ${ }^{1}$; ÂNGELO. Humberto ${ }^{2}$. DEMANDA DE BRIQUETE DE MADEIRA. Floresta, Curitiba, PR, v. 41, n, 1, p. 73-78, jan./mar. 2011. Alemida, A, N. de et al. 


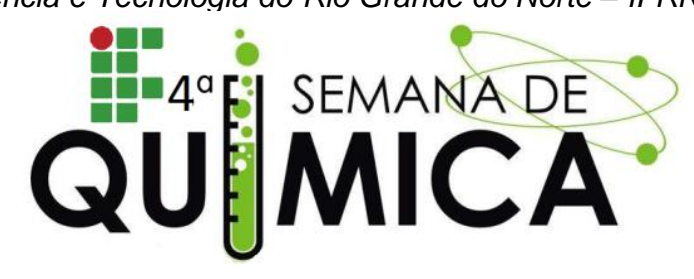

\section{SÍNTESE DE COMPLEXOS DE Cu $\mathrm{Cu}^{2+} \mathrm{E} \mathrm{Co}^{3+}$ A PARTIR DO CuSO $4.5 \mathrm{H}_{2} \mathrm{O}$ E DO $\mathrm{CoCl}_{2.6} \mathrm{H}_{2} \mathrm{O}$ COM LIGANTES $\mathrm{NH}_{3}$}

LINS, F. C. C. (IFRN); MEDEIROS, J. (IFRN); SOUZA, D. S. (ORIENTADORA)

Palavras Chave: Composto de Coordenação, Síntese, Ligantes.

\section{INTRODUÇÃO}

Os compostos de coordenação são substâncias que contém um metal central envolvido de ligantes, que fazem função de bases de Lewis. Neste trabalho, foi realizada a síntese dos complexos $\left[\mathrm{Cu}\left(\mathrm{NH}_{3}\right)_{6}\right]^{2+}$ e $\left[\mathrm{Co}\left(\mathrm{NH}_{3}\right)_{6}\right] \mathrm{Cl}_{3}$ a partir dos sais $\mathrm{CuSO}_{4} .5 \mathrm{H}_{2} \mathrm{O}$ e $\mathrm{CoCl}_{2} .6 \mathrm{H}_{2} \mathrm{O}$, respectivamente. De acordo com a teoria de Werner, as ligações coordenadas são formadas entre os ligantes e o íon metálico central do complexo, isto é, o ligante doa um par de elétrons ao íon metálico.

\section{METODOLOGIA}

Reagentes: $\mathrm{CuSO}_{4} .5 \mathrm{H}_{2} \mathrm{O} ; \mathrm{NH}_{4} \mathrm{OH}$ P.A; $\mathrm{C}_{2} \mathrm{H}_{6} \mathrm{O}$ (70\%); Água destilada; $\mathrm{CoCl}_{2} .6 \mathrm{H}_{2} \mathrm{O}$; $\mathrm{NH}_{4} \mathrm{Cl} ; \mathrm{H}_{2} \mathrm{O}_{2}$ (35\%); $\mathrm{HCl}$ (concentrado); Carvão ativado.

Materiais e equipamentos: Béquer; Espátula; Pipeta; Placas de Petri; Funil de Buchner; Kitassato; Bastão de vidro; Rolhas; Papel de filtro qualitativo; Mangueiras para conexão; Pinça metálica; Balança analítica; Bomba de vácuo; Dessecador; Agitador magnético; Estufa; Capela de exaustão.

\section{Procedimento}

experimental:

Inicialmente para o preparo do hexaminocobre (II) foi pesado na balança analítica $14 \mathrm{~g}$ de $\mathrm{CuSO}_{4} .5 \mathrm{H}_{2} \mathrm{O}$, em seguida o material foi dissolvido em $60 \mathrm{~mL}$ de água destilada agitando-se até a solubilidade do mesmo. Logo após, a substância foi levada até a capela de exaustão para o acréscimo de $30,4 \mathrm{~mL}$ de $\mathrm{NH}_{4} \mathrm{OH}$, após a adição, $100 \mathrm{~mL}$ de álcool etílico
$70 \%$ foi acrescentado à mistura verificando-se a formação do complexo com coloração azul intensa. O precipitado foi filtrado a vácuo, deixado 12 horas no dessecador e, posteriormente, duas horas na estufa à temperatura de $70 \circ \mathrm{C}$.

Para a síntese do complexo cloreto de Hexamincobalto (III) foi utilizado $24 \mathrm{~g}$ de $\mathrm{CoCl}_{2} \cdot 6 \mathrm{H}_{2} \mathrm{O}$, misturado com $16 \mathrm{~g}$ de $\mathrm{NH}_{4} \mathrm{Cl}$ em $20 \mathrm{~mL}$ de água. Após a dissolução dos reagentes, misturou-se $50 \mathrm{~mL}$ de $\mathrm{NH}_{4} \mathrm{OH}$ e $1 \mathrm{~g}$ de carvão ativado. A mistura foi resfriada até atingir à temperatura de 10 드, então se adicionou gota a gota $10 \mathrm{~mL}$ de peróxido de hidrogênio, $\mathrm{H}_{2} \mathrm{O}_{2}$ (35\%), mantendo a solução em agitação e elevando a temperatura a $60 \circ \mathrm{C}$ por 30 minutos. Em seguida, foi resfriada até atingir $0 \circ \mathrm{C}$. Após o processo de resfriamento, a mistura foi filtrada e se adicionou uma mistura de $150 \mathrm{~mL}$ de água fervente e $25 \mathrm{~mL}$ de $\mathrm{HCl}_{\text {(concentrado), onde foi feita uma outra filtração }}$ para a remoção do carvão. O filtrado foi misturado a uma solução de $\mathrm{HCl}_{\text {(concentrado) }} \mathrm{em}$ água a temperatura de $0 \circ \mathrm{C}$, ocorrendo a precipitação do complexo, que foi filtrado em seguida lavado com duas soluções de álcool etílico $60 \%$ e 95\%, respectivamente. O complexo foi posto a temperatura ambiente para secagem durante sete dias.

\section{RESULTADOS E DISCUSSÕES}

A formação composto de coordenação hexamincobre (II) (vide figura 01) pode ser demonstrada pelas equações abaixo: 
Inicialmente temos:

$\mathrm{CuSO}_{4} .5 \mathrm{H}_{2} \mathrm{O}+4 \mathrm{NH}_{4} \mathrm{OH} \rightarrow \mathrm{Cu}\left(\mathrm{NH}_{3}\right)_{4} \mathrm{SO}_{4} \cdot \mathrm{H}_{2} \mathrm{O}$ $+8 \mathrm{H}_{2} \mathrm{O}$

(01)

Em seguida, ao adicionarmos peróxido de hidrogênio e etanol, ocorre a formação do complexo de acordo com a equação (02):

$\mathrm{Cu}\left(\mathrm{NH}_{3}\right)_{4} \mathrm{SO}_{4} \cdot \mathrm{H}_{2} \mathrm{O}+\mathrm{H}_{2} \mathrm{O}_{2}+\mathrm{C}_{2} \mathrm{H}_{6} \mathrm{O} \rightarrow$
$\left[\mathrm{Cu}\left(\mathrm{NH}_{3}\right)_{6}\right]^{2+}+\mathrm{SO}_{4}^{-}+\mathrm{H}_{2} \mathrm{O}+\mathrm{C}_{2} \mathrm{H}_{6} \mathrm{O}$

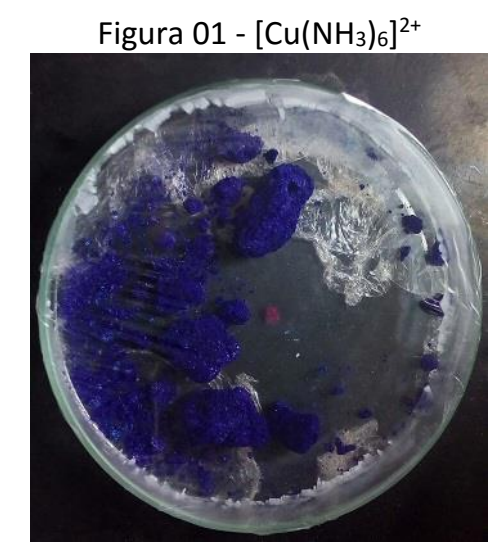

(Fonte própria)

Para o composto Cloreto de Hexaamincobalto (vide figura 02) (III) a equação balanceada obtida foi:

$4 \mathrm{CoCl}_{2}+4 \mathrm{H}_{4} \mathrm{Cl}+20 \mathrm{NH}_{3}+\mathrm{O}_{2} \rightarrow 4\left[\mathrm{Co}\left(\mathrm{NH}_{3}\right)_{6}\right] \mathrm{Cl}_{3}+$ $2 \mathrm{H}_{2} \mathrm{O}$

(03)

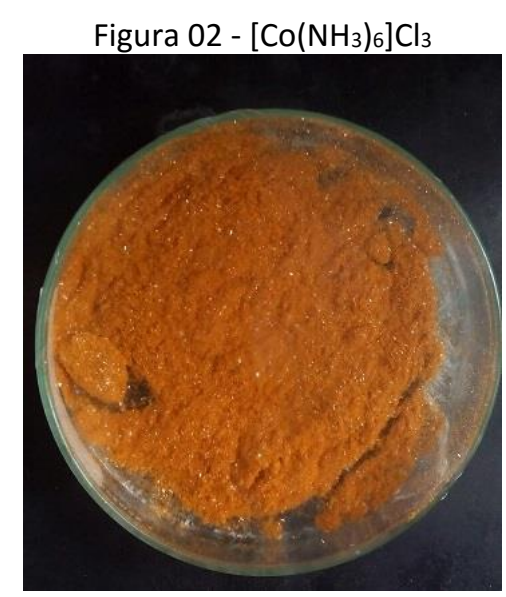

(Fonte própria)

Após a obtenção dos complexos foram observados os seguintes rendimentos, utilizando-se uma regra de três simples, entre as massas molares dos complexos formados e os sais base para a formação do mesmo. Conforme a dados abaixo:
Massa molar do CuSO $4.5 \mathrm{H}_{2} \mathrm{O}=249,6850 \mathrm{~g} \cdot \mathrm{mol}^{-1}$ Massa molar do $\left[\mathrm{Cu}\left(\mathrm{NH}_{3}\right)_{6}\right]^{2+}=165,7280 \mathrm{~g} \cdot \mathrm{mol}^{-1}$

Logo, 249,6 gramas do sal deveriam gerar 165,7 gramas do complexo. Como utilizamos 14 gramas do sal deveríamos obter cerca de 9,242 gramas do complexo que corresponderia a $100 \%$ de rendimento. Mas o obtido foi de 5,6241 gramas que corresponde a $60,52 \%$ de rendimento.

Fazendo a mesma analogia para o complexo $\left[\mathrm{Co}\left(\mathrm{NH}_{3}\right)_{6}\right] \mathrm{Cl}_{3}$ temos:

Massa molar do $\mathrm{CoCl}_{2} \cdot 6 \mathrm{H}_{2} \mathrm{O}=237,9309 \mathrm{~g} \cdot \mathrm{mol}^{-1}$ Massa molar do $\left[\mathrm{Co}\left(\mathrm{NH}_{3}\right)_{6}\right] \mathrm{Cl}_{3}=267,4753 \mathrm{~g} \cdot \mathrm{mol}^{-1}$

Nesse caso, para um rendimento de 100\% deveríamos obter 10,117 gramas do composto formado, pois utilizamos 9 gramas de cloreto de cobalto. Como obtemos apenas 3,7330 gramas, o rendimento obtido foi de $36,89 \%$.

\section{CONCLUSÃO}

A partir do estudo feito foi possível sintetizar os compostos de coordenação em questão utilizando o aparato presente nos laboratórios do Instituto Federal do Rio Grande do Norte, campus de Nova Cruz e compreender como são formados tais compostos e seus meios reacionais, obtendo resultado satisfatório para ambos os complexos envolvidos.

\section{REFERÊNCIAS}

${ }^{1}$ FARIAS, R. F. Práticas de Química Inorgânica. Campinas, SP: Editora Átomo, 2013.

${ }^{2}$ FARIAS, R. F. Química de Coordenação: fundamentos e atualidades. Campinas/SP: Editora Átomo, 2009.

${ }^{3}$ SOUZA, M. M. V. M. Processos Inorgânicos. Rio de Janeiro: Synergia, 2012.

${ }^{4}$ RIBEIRO, M. A. Estudo de compostos de coordenação de cobalto e labilidade eletrônica. UFMG: departamento de química, 2013.

${ }^{5}$ MONSALVE, M. S. Síntese e caracterização de compostos de coordenação mistos de cobre com potencial atividade anti-Mycobacterium tuberculosis. USP: Instituto de química, 2013. 